\title{
Benzoyl ester formation in Aspergillus ustus by hijacking the polyketide acyl intermediates with alcohols
}

\author{
Liujuan Zheng ${ }^{1} \cdot$ Shu-Ming Li ${ }^{1}$ (i)
}

Received: 2 December 2020 / Revised: 21 December 2020 / Accepted: 4 January 2021 / Published online: 22 January 2021

(c) The Author(s) 2021

\begin{abstract}
Accumulation of two benzoyl esters in Aspergillus ustus after feeding with alcohols was reported 30 years ago. To the best of our knowledge, the biosynthesis for these esters has not been elucidated prior to this study. Here, we demonstrate that these compounds are artifical products of the phenethyl polyketide ustethylin A biosynthestic pathway. In addition, four aditional benzoyl esters with different methylation levels were also isolated and identified as shunt products. Feeding experiments provided evidence that the enzyme-bound polyketide acyl intermediates are hijacked by externally fed $\mathrm{MeOH}$ or EtOH, leading to the formation of the benzoyl esters.
\end{abstract}

\section{Graphic abstract}

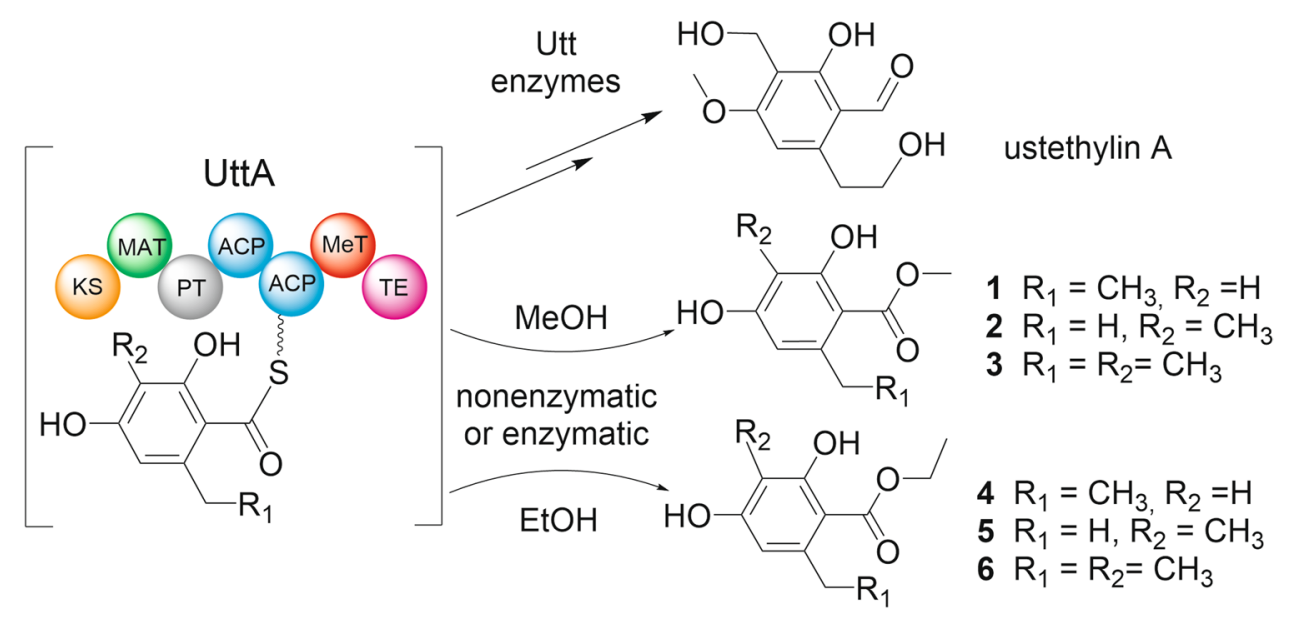

Keywords Benzoyl esters $\cdot$ Biosynthesis $\cdot$ Aspergillus ustus $\cdot$ Alcohols feeding $\cdot$ Polyketides

Communicated by Erko Stackebrandt.

Supplementary Information The online version contains supplementary material available at https://doi.org/10.1007/s0020 3-021-02182-0.

Shu-Ming Li

shuming.li@staff.uni-marburg.de

1 Institut für Pharmazeutische Biologie und Biotechnologie, Fachbereich Pharmazie, Philipps-Universität Marburg, Robert-Koch Straße 4, 35037 Marburg, Germany

\section{Introduction}

Secondary metabolites play an important role in ecological fitness of microorganisms, such as for protection from UV damage, toxic natural products and other microorganisms (Keller 2019). Polyketides with diverse biological and pharmacological activities are the most abundant fungal natural products (Keller et al. 2005; Ran and Li 2020). These compounds are biosynthesized by the well-studied multidomain proteins-polyketide synthases (PKSs). Based on the reduction status of their products, fungal PKSs can basically be 
divided into three class: nonreducing, partially reducing and highly reducing PKSs (Cox 2007). The typical nonreducing PKSs contain starter unit ACP transacylase (SAT), ketosynthase (KS), malonyl-CoA-ACP transacylase (MAT), product template (PT), acyl-carrier protein (ACP) and thioesterase (TE) domains (Crawford and Townsend 2010).

A study in 1987 reported the accumulation of 2,4-dihydroxy-3-methyl-6-ethyl benzoyl methyl and ethyl ester after feeding an Aspergillus ustus culture with $\mathrm{MeOH}$ and $\mathrm{EtOH}$, respectively. Isotope incorporation was observed for both methyl groups of the aryl acid after feeding with [methyl- ${ }^{13} \mathrm{C}$ ]-L-methionine, indicating their origin from methylation. Isotope labeling experiments also proved that other carbons are derived from acetate (De Jesus et al. 1987). However, no further biosynthetic studies have been reported for these compounds.

Phenethyl-containing compounds are common microbial metabolites. In fungi, the ethyl groups in phenethyl residue are derived from $S$-adenosyl L-methionine and usually catalyzed by the methyltransferase domain of polyketide synthase (Zheng et al. 2020). Recently, we elucidated the first biosynthetic pathway of fungal phenethyl derivatives, i.e., that of ustethylin A in A. ustus 3.3904 (Zheng et al. 2020), a rare human pathogen fungus (Pi et al. 2015). In this pathway, the nonreducing PKS UttA is responsible for the formation of the key intermediate phenethyl benzoic acid. After reduction of the aryl carboxyl group to aldehyde by the NRPS-like enzyme UttJ, the methyl and ethyl groups are oxidized by the nonheme $\mathrm{Fe}^{\mathrm{II}} / 2$-oxoglutarate-dependent oxygenase $\mathrm{UttH}$ and the cytochrome $\mathrm{P}_{450}$ enzyme UttC, respectively. Phenolic methylation is catalyzed by the methyltransferase $\mathrm{UttF}$ (Scheme 1). The final pathway product ustethylin A was detected as the predominantly accumulated metabolite (Fig. 1a).

\section{Materials and methods}

\section{Strains, media and growth conditions}

Aspergillus ustus 3.3904 was purchased from China General Microbiological Culture Collection Center (Beijing, China) and cultivated in PDB (potato dextrose broth, Sigma) medium at $230 \mathrm{rpm}$ and $30{ }^{\circ} \mathrm{C}$ for secondary metabolite production. Construction of the A. ustus $\triangle u t t A$ mutant has been reported previously (Zheng et al. 2020).

\section{Alcoholic feeding experiments}

$1.5 \mathrm{~mL}(3 \%, \mathrm{v} / \mathrm{v})$ of $\mathrm{MeOH}, \mathrm{EtOH}$ or $\mathrm{CD}_{3} \mathrm{OD}$ were added into the three day-old A. ustus cultures in $250 \mathrm{~mL}$ flask containing $50 \mathrm{~mL}$ PDB medium, which were further maintained at $230 \mathrm{rpm}$ and $30^{\circ} \mathrm{C}$ for five days. $1 \mathrm{~mL}$ culture was extracted with EtOAc for LC-MS analysis.

For large-scale fermentation, $15 \mathrm{~mL}$ of $\mathrm{MeOH}$ or $\mathrm{EtOH}$ were added to $500 \mathrm{~mL}$ PDB medium in $2 \mathrm{~L}$ flask and cultivated under the same condition as mentioned above.

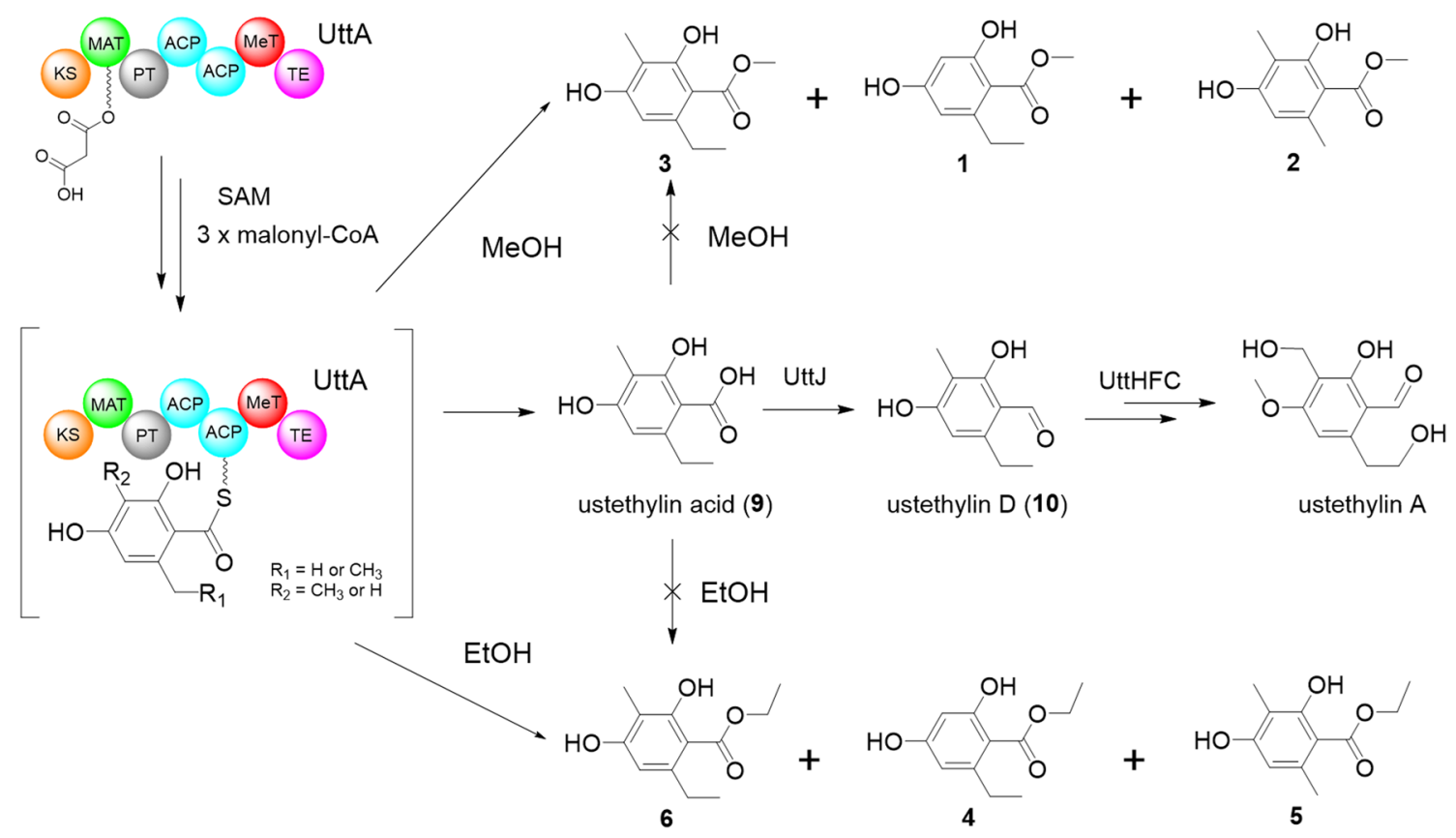

Scheme 1. Simplified biosynthetic pathway of ustethylin A with 1-6 as shunt products after alcoholic feeding 


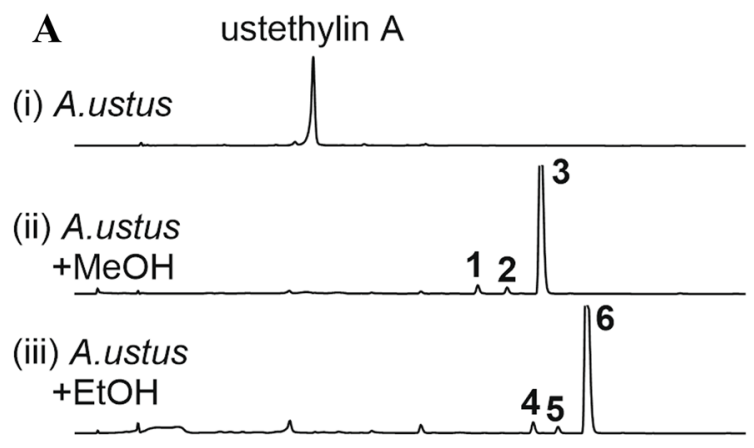

(iv) A.ustus $\Delta u t t A$

(v) A.ustus $\triangle$ uttA+MeOH

(vi) A.ustus

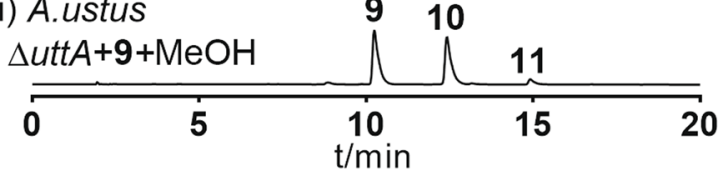

B
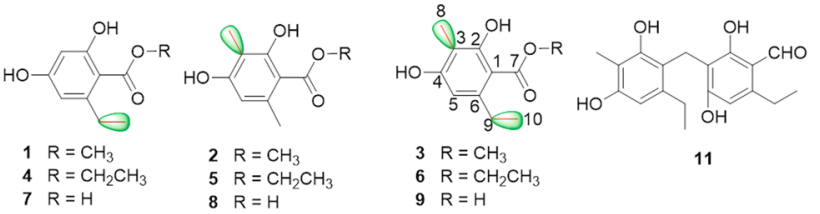

$7 \mathrm{R}=\mathrm{H}$

$5 \mathrm{R}=\mathrm{CH}$

$9 \mathrm{R}=\mathrm{H}$

Fig. 1 a HPLC analysis of the A. ustus extracts. UV detection was carried on a photodiode array detector and absorptions at $254 \mathrm{~nm}$ are illustrated. b Structures of 1-9 and 11

\section{Precursor feeding in $\Delta u t t A$ mutant}

Compound 9 was dissolved in $\mathrm{MeOH}$ at a concentration of $18 \mathrm{mg} / \mathrm{mL}$. $277 \mu \mathrm{L}(5 \mathrm{mg})$ of this solution were added into the culture of the A. ustus $\triangle$ uttA mutant in $250 \mathrm{~mL}$ flask containing $50 \mathrm{~mL}$ PDB medium after fermentation at $230 \mathrm{rpm}$ and $30{ }^{\circ} \mathrm{C}$ for three days. Two days later, $1 \mathrm{~mL}$ culture was extracted with EtOAc for LC-MS analysis.

\section{HPLC analysis and isolation}

Extracts were analyzed on an Agilent HPLC series 1200 (Agilent Technologies) equipped with an Agilent Eclipse XDB-C18 column $(5 \mu \mathrm{m}, 4.6 \times 150 \mathrm{~mm})$. A linear gradient from 10 to $90 \%$ ACN in $\mathrm{H}_{2} \mathrm{O}$ in 20 min was used. The column was then washed with $100 \% \mathrm{ACN}$ for $5 \mathrm{~min}$ and equilibrated with $10 \% \mathrm{ACN}$ in $\mathrm{H}_{2} \mathrm{O}$ for another 5 min. Detection was carried out on a photodiode array detector and absorptions at $254 \mathrm{~nm}$ are illustrated in this study.
A semi-preparative Multospher 120 RP-18 column $(5 \mu \mathrm{m}$, $10 \times 250 \mathrm{~mm}$ ) was used for isolation of the products for structural elucidation on the same HPLC system with the same solvents at a flow rate of $2 \mathrm{~mL} / \mathrm{min}$. Separation was done by isocratic elution with $25-70 \%$ ACN for 10-20 min.

\section{Large-scale fermentation, extraction and isolation of secondary metabolites}

For isolation of compounds $\mathbf{1 - 3}$, large-scale fermentation of A. ustus 3.3904 with $\mathrm{MeOH}$ was carried out as described above. The supernatant was separated from mycelia by filtration and extracted with equal volume of EtOAc for three times. The mycelia were extracted with acetone and concentrated under reduced pressure to afford an aqueous solution and then extracted with EtOAc for three times. Both EtOAc extracts were evaporated under reduced pressure to afford the crude extracts for further purification. The crude extract was separated on a silica gel column with $\mathrm{CHCl}_{3} /$ $\mathrm{MeOH}$ (100:0-0:100) as elution solvents to give 8 fractions. Fraction 2 was purified on a semi-preparative HPLC (ACN/ $\mathrm{H}_{2} \mathrm{O}$ ), leading to $8.0 \mathrm{mg}$ of $\mathbf{1}, 8.0 \mathrm{mg}$ of 2 and $60.0 \mathrm{mg}$ of $\mathbf{3}$. Similar procedure was used for product isolation after EtOH feeding. $6.5 \mathrm{mg}$ of $\mathbf{4}, 5.2 \mathrm{mg}$ of $\mathbf{5}$ and $30.0 \mathrm{mg}$ of $\mathbf{6}$ were obtained in high purity.

\section{LC-MS and MS analysis}

Extracts were also analyzed on an Agilent HPLC 1260 series system equipped with a Bruker microTOF QIII mass spectrometer using an Agilent Eclipse XDB C18 column $(5 \mu \mathrm{m}$, $4.6 \times 150 \mathrm{~mm})$. Separation was performed at a flow rate of $0.5 \mathrm{~mL} / \mathrm{min}$ with a $40 \mathrm{~min}$ linear gradient from 5 to $100 \%$ $\mathrm{ACN}$ in $\mathrm{H}_{2} \mathrm{O}$, both containing $0.1 \%$ (v/v) $\mathrm{HCOOH}$. The column was then washed with $100 \% \mathrm{ACN}$ for 5 min and equilibrated for 5 min with $5 \% \mathrm{ACN}$ in $\mathrm{H}_{2} \mathrm{O}$. The parameters of the spectrometer were set as the following: electrospray positive ion mode for ionization, capillary voltage with $4.5 \mathrm{kV}$, collision energy with $8.0 \mathrm{eV}$. Sodium formate was used in each run for mass calibration. The masses were scanned in the range of $m / z$ 100-1500. Data were evaluated with the Compass DataAnalysis 4.2 software (Bruker Daltonik, Bremen, Germany).

\section{NMR analysis}

NMR spectra of the isolated products were recorded at room temperature on a JEOL ECA-500 (JEOL, Akishima, Tokyo, Japan). The samples were dissolved in $\mathrm{CDCl}_{3}$ or $\mathrm{CD}_{3} \mathrm{OD}$. All spectra were processed with MestReNov.9.0.0 (Mestrelab Research, Santiago de Compostella, Spain). 


\section{Physiochemical properties of the compounds described in this study}

1: white needle crystal; ${ }^{1} \mathrm{H}$ NMR data see Table S1; HRMS (ESI) $m / z:[\mathrm{M}+\mathrm{H}]^{+}$calcd. for $\mathrm{C}_{10} \mathrm{H}_{13} \mathrm{O}_{4}$ 197.0808; found 197.0756.

2: white needle crystal; ${ }^{1} \mathrm{H}$ NMR data see Table S1; HRMS (ESI) $m / z:[\mathrm{M}+\mathrm{H}]^{+}$calcd. for $\mathrm{C}_{10} \mathrm{H}_{13} \mathrm{O}_{4}$ 197.0808; found 197.0755 .

3: white bulk crystal; ${ }^{1} \mathrm{H}$ NMR data see Table $\mathrm{S} 1,{ }^{13} \mathrm{C}$ NMR data see Table S2; HRMS (ESI) $m / z:[\mathrm{M}+\mathrm{H}]^{+}$calcd. for $\mathrm{C}_{11} \mathrm{H}_{15} \mathrm{O}_{4} 211.0965$; found 211.0916.

4: white needle crystal; ${ }^{1} \mathrm{H}$ NMR data see Table S1; HRMS (ESI) $m / z:[\mathrm{M}+\mathrm{H}]^{+}$calcd. for $\mathrm{C}_{11} \mathrm{H}_{15} \mathrm{O}_{4} 211.0965$; found 211.0964 .

5: white needle crystal; ${ }^{1} \mathrm{H}$ NMR data see Table S1; HRMS (ESI) $m / z:[\mathrm{M}+\mathrm{H}]^{+}$calcd. for $\mathrm{C}_{11} \mathrm{H}_{15} \mathrm{O}_{4} 211.0965$; found 211.0960 .

6: white bulk crystal; ${ }^{1} \mathrm{H}$ NMR data see Table S1; HRMS (ESI) $m / z:[\mathrm{M}+\mathrm{H}]^{+}$calcd. for $\mathrm{C}_{12} \mathrm{H}_{17} \mathrm{O}_{4} 225.1121$; found 225.1119 .

\section{Structural elucidation}

The structures of the isolated products were elucidated by interpretation of their MS and NMR spectra (Figures S1-S9) and by comparison of these data with those described in the literature. 1 (Sher and Langer 2008), 2 (Schleich et al. 2006)
3 (De Jesus et al. 1987), 4 (Schleich et al. 2006), 5 (Sher and Langer 2008) and 6 (De Jesus et al. 1987) were identified as known compounds.

\section{Results and discussion}

The aryl acids involved in the biosynthesis of ustethylins are the acyl components of the previously identified esters (De Jesus et al. 1987) (Fig. 1b). We speculated therefore that they are also derived from the ustethylin pathway. To prove our hypothesis, we repeated the feeding experiments with alcohols using three day-old cultures of A. ustus 3.3904 wild-type and an uttA deficient mutant in PDB medium. As shown in Fig. 1a, HPLC analysis of the EtOAc extract of the wild-type revealed the presence of ustethylin A as the predominant metabolite (Fig. 1a), as reported previously (Zheng et al. 2020). In the extract of the culture with externally fed $\mathrm{MeOH}$ and $\mathrm{EtOH}$, three metabolites each 1-3 and 4-6 were detected, respectively. $\mathbf{3}$ as a major peak was accompanied by two minor ones $\mathbf{1}$ and $\mathbf{2}$ in the culture with $\mathrm{MeOH}$. LC-MS analysis revealed that $\mathbf{3}$ has an additional methyl group than $\mathbf{1}$ and $\mathbf{2}$ (Fig. 2a). It is noteworthy that compounds 1, 2, 4 and 5 were not reported in the previous study (De Jesus et al. 1987).

For structural elucidation, $\mathbf{1}-\mathbf{3}$ were isolated from a 2 L A. ustus culture after feeding with $60 \mathrm{~mL} \mathrm{MeOH}$. Comparison of the NMR data of the isolated products (Tables
Fig. 2 LC-MS results (positive mode) of $A$. ustus extracts after feeding with $\mathrm{MeOH}$ (a) and $\mathrm{CD}_{3} \mathrm{OD}$ (b). UV absorptions at $254 \mathrm{~nm}$ are illustrated
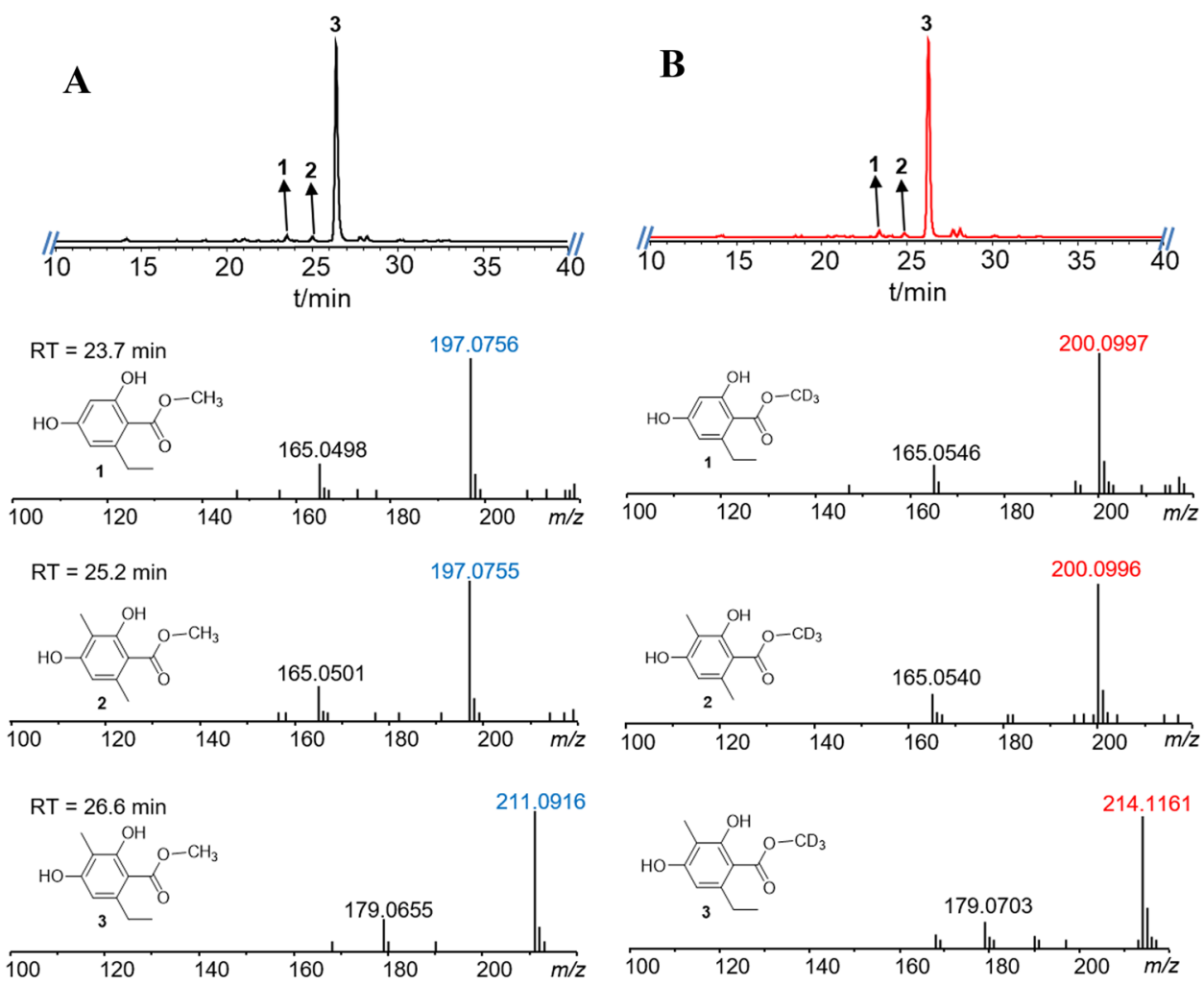
S1 and S2, Figures S1-S6) with those described in the literature confirmed 3 to be 2,4-dihydroxy-3-methyl-6-ethyl benzoyl methyl ester (De Jesus et al. 1987). NMR analysis also proved that $\mathbf{1}$ and $\mathbf{2}$ are two congeners of $\mathbf{3}$ lacking the $C 3$-methyl group and replacing the $C 6$-ethyl by a methyl group, respectively (Fig. 1b) (De Jesus et al. 1987; Schleich et al. 2006; Sher and Langer 2008). In analogy, the major peak $\mathbf{6}$ and the two minor ones $\mathbf{4}$ and $\mathbf{5}$ were also isolated from the culture fed with EtOH and identified as ethyl esters of the corresponding aryl acids (De Jesus et al. 1987; Schleich et al. 2006; Sher and Langer 2008) (Fig. 1b, Table S1, Figures S7-S9).

The isotopic feeding experiments in the previous study proved that the $O$-methyl group in compound $\mathbf{3}$ is not derived from methionine (De Jesus et al. 1987). The $O$-methyl groups in 1-3 originate likely from $\mathrm{MeOH}$. To confirm this, $\mathrm{CD}_{3} \mathrm{OD}$ was fed into the Aspergillus ustus culture and the EtOAc extract was analyzed via HPLC-MS. Detection of $[\mathrm{M}+\mathrm{H}]^{+}$ion of $\mathbf{3}$ at $\mathrm{m} / \mathrm{z} 214.1161$ after feeding with $\mathrm{CD}_{3} \mathrm{OD}, 3$ Daltons larger than that after feeding with $\mathrm{MeOH}$ at $m / z 211.0916$ (Fig. 2), proved the incorporation of the $\mathrm{CD}_{3}$ group into the structure of 3 . Similar MS pattern changes were also observed for compounds 1 and $\mathbf{2}$ (Fig. 2).

As reported previously (Zheng et al. 2020), the PKS UttA from the ustethylin biosynthetic pathway is responsible for the formation of the aryl acids 7-9 (Fig. 1b), the acyl moieties of 1-3 and 4-6. To prove its function, uttA was replaced with a hygromycin B resistance cassette in our former study (Zheng et al. 2020). HPLC analysis of the culture extract of the $\Delta u t t A$ mutant revealed the abolishment of ustethylin A production. Feeding this $\Delta u t t A$ mutant with $\mathrm{MeOH}$ did not lead to an accumulation of 1-3 (Fig. 1a). Similar results were also observed after feeding the $\Delta u t t A$ mutant with $\mathrm{EtOH}$ (data not shown). This proved unequivocally the involvement of UttA in the formation of 1-6.

To figure out whether the ester formation is from free acids in A. ustus, $\mathbf{9}$ in $\mathrm{MeOH}$ was fed to the culture of $\Delta u t t A$ mutant. As shown in Fig. 1a, no trace of $\mathbf{3}$ was detected. Instead, 9 was converted to the corresponding benzaldehyde $\mathbf{1 0}$ (ustethylin D) and a dimeric metabolite 11, as described previously (Zheng et al. 2020). In addition, $\mathbf{3}$ was not detected after incubation of 9 with $\mathrm{MeOH}$ at $37{ }^{\circ} \mathrm{C}$ for $16 \mathrm{~h}$ (data not shown). These results indicated that the ester formation in 1-6 requires activation of the acidic precursors.

In the previous study, we proposed that the PKS UttA utilizes malonyl-CoA as both starter and extension unit. Two methylation steps, at C-3 of the benzene ring and the C6-methyl group, are involved in the formation of the aryl acyl-ACP molecules (Scheme 1), which are then released as free aryl acids and modified by tailoring enzymes. Our results in this study provide evidence that after the phenyl ring formation catalyzed by UttA, the acyl-ACP molecules can be hijacked by alcohols for ester formation, as depicted in Scheme 1. The formation of the minor products $\mathbf{1}$ and $\mathbf{2}$ after feeding with $\mathrm{MeOH}$ as well as $\mathbf{4}$ and $\mathbf{5}$ after feeding with EtOH confirmed the incomplete methylation steps by UttA, as observed in the previous study (Zheng et al. 2020). In vivo assays in our aforementioned study verified that reduction of the acid $\mathbf{9}$ to the benzaldehyde $\mathbf{1 0}$ by the NRPS-like enzyme UttJ is a prerequisite for further modification (Zheng et al. 2020). Therefore, the esters 1-6 cannot be further metabolized by the tailoring enzymes of the Utt pathway and were accumulated as artificial products.

Feeding n-PrOH to the culture of A. ustus wild-type led to the detection of trace amount of the corresponding ester by HPLC-MS analysis, which could not be isolated in substantial amount for structural identification. No ester formation was observed after feeding with $\mathrm{i}-\mathrm{PrOH}$ or $\mathrm{n}-\mathrm{BuOH}$ (data not shown). These results indicated that the ester formation is preferred for small alcohols. Ester bonds are commonly present in natural products and are usually formed during chain release in the polyketide (Wang et al. 2009) or nonribosomal peptide biosynthesis and by Baeyer-Villiger monooxygenases (Tsakos et al. 2015). However, spontaneous ester formation has also been described for carboxylic acids by incubation in alcoholic solvents at room temperature (Fan et al. 2020). Therefore, it cannot be concluded whether the formation of 1-6 is an enzymatic or nonenzymatic event (Scheme 1).

\section{Conclusions}

In conclusion, we demonstrated in this study that the aryl acyl esters from A. ustus 3.3904 are shunt products of the ustethylin biosynthetic pathway as response for the externally fed alcohols. It will be interesting to investigate the physiological relevance of this response.

Acknowledgements We thank Rixa Kraut, Lena Ludwig-Radtke and Stefan Newel for taking MS and NMR spectra. This project was financially funded in part by the Deutsche Forschungsgemeinschaft (DFG, INST 160/620-1). Liujuan Zheng (201604910536) is scholarship recipient from the China Scholarship Council.

Funding Open Access funding enabled and organized by Projekt DEAL.

\section{Compliance with ethical standards}

Conflict of interest There are no conflicts to declare.

Open Access This article is licensed under a Creative Commons Attribution 4.0 International License, which permits use, sharing, adaptation, distribution and reproduction in any medium or format, as long as you give appropriate credit to the original author(s) and the source, provide a link to the Creative Commons licence, and indicate if changes were made. The images or other third party material in this article are 
included in the article's Creative Commons licence, unless indicated otherwise in a credit line to the material. If material is not included in the article's Creative Commons licence and your intended use is not permitted by statutory regulation or exceeds the permitted use, you will need to obtain permission directly from the copyright holder. To view a copy of this licence, visit http://creativecommons.org/licenses/by/4.0/.

\section{References}

Cox RJ (2007) Polyketides, proteins and genes in fungi: programmed nano-machines begin to reveal their secrets. Org Biomol Chem 5:2010-2026

Crawford JM, Townsend CA (2010) New insights into the formation of fungal aromatic polyketides. Nat Rev Microbiol 8:879-889

De Jesus AE, Horak RM, Steyn PS, Vleggaar R (1987) Metabolites of Aspergillus ustus. Part 4. Stable-isotope labelling studies on the biosynthesis of the austalides. J Chem Soc, Perkin Trans 12253-2257

Fan J, Liao G, Ludwig-Radtke L, Yin W-B, Li S-M (2020) Formation of terrestric acid in Penicillium crustosum requires redox-assisted decarboxylation and stereoisomerization. Org Lett 22:88-92

Keller NP (2019) Fungal secondary metabolism: regulation, function and drug discovery. Nat Rev Microbiol 17:167-180

Keller NP, Turner G, Bennett JW (2005) Fungal secondary metabolism-from biochemistry to genomics. Nat Rev Microbiol 3:937-947
Pi B, Yu D, Dai F, Song X, Zhu C, Li H, Yu Y (2015) A genomics based discovery of secondary metabolite biosynthetic gene clusters in Aspergillus ustus. PLoS ONE 10:e0116089

Ran H, Li S-M (2021) Fungal benzene carbaldehydes: occurrence, structural diversity, activities and biosynthesis. Nat Prod Rep. https://doi.org/10.1039/D0NP00026D

Schleich S, Papaioannou M, Baniahmad A, Matusch R (2006) Activityguided isolation of an antiandrogenic compound of Pygeum africanum. Planta Med 72:547-551

Sher M, Langer P (2008) Regioselective synthesis of functionalized resorcins by cyclization of 1,3-bis(trimethylsilyloxy)-1,3-butadienes with 3,3-dimethoxypentanoyl chloride. Synlett1050-1052

Tsakos M, Schaffert ES, Clement LL, Villadsen NL, Poulsen TB (2015) Ester coupling reactions - an enduring challenge in the chemical synthesis of bioactive natural products. Nat Prod Rep 32:605-632

Wang M, Zhou H, Wirz M, Tang Y, Boddy CN (2009) A thioesterase from an iterative fungal polyketide synthase shows macrocyclization and cross coupling activity and may play a role in controlling iterative cycling through product offloading. Biochemistry 48:6288-6290

Zheng L, Yang Y, Wang H, Fan A, Zhang L, Li S-M (2020) Ustethylin biosynthesis implies phenethyl derivative formation in Aspergillus ustus. Org Lett 22:7837-7841

Publisher's Note Springer Nature remains neutral with regard to jurisdictional claims in published maps and institutional affiliations. 